\title{
Understanding magmatic processes prior to the 1257 CE Mount Samalas eruption through plagioclase zoning patterns
}

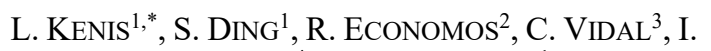
PRATOMO $^{4}$, M.-A. LONGPRÉ ${ }^{1}$

${ }^{1}$ CUNY Queens College, Flushing, NY, USA

(*Lexi.Kenis87@qmail.cuny.edu)

${ }^{2}$ Southern Methodist University, Dallas, TX, USA

${ }^{3}$ University of Cambridge, Cambridge, UK

${ }^{4}$ Geological Museum, Bandung, Indonesia

The 1257 CE eruption of Mount Samalas (Lombok, Indonesia) is one of the largest volcanic events of the Holocene and had global climate repercussions lasting several years [1-3]. Previous work has shown that the eruption evacuated an homogenous trachydacite magma body containing 6-17 vol.\% crystals comprised mostly of plagioclase, amphibole, and orthopyroxene $[3,4]$. In this work, we combine backscatter electron imaging and electron probe micro-analysis to take a closer look at the zoning patterns of plagioclase phenocrysts extracted from pumice samples in order to further constrain the magmatic processes and conditions prevailing in the lead up to eruption. The composition of 1257 plagioclase phenocrysts displays a bimodal distribution, with prominent modes at An57-82 and An52-56, consistent with previous work [3,4]. Two broad types of crystals are observed: (1) normally zoned, with a high-An core, which may be patchy, and a wide low-An rim, and (2) weakly oscillatory zoned without a high-An core. In detail, electron probe traverses reveal that the $\sim 300-\mu \mathrm{m}$-thick lowAn rims of several crystals across these groups actually display progressive reverse zoning from minima of $\mathrm{An}_{40-45}$ in their inner parts to maxima of $\sim \mathrm{An}_{55}$ in contact with glass. These observations suggest that final assembly of the 1257 trachydacite magma involved compositional and/or thermal rejuvenation. Based on evidence of reequilibration of $\mathrm{Mg}$ concentrations in plagioclase [4], this work attempts to constrain the timescales of magma reservoir buildup prior to the 1257 eruption.

[1] Lavigne et al. (2013), PNAS; [2] Vidal et al. (2016), Sci. Rep.; [3] Guillet et al. (2017), Nat. Geosci.; [4] Métrich et al. (2018), JPet 